\title{
The Psychometric Properties of the Roland Morris Disability Questionnaire for Patients with Chronic Mechanical Low Back Pain
}

\begin{abstract}
Purpose: Functional status measures are currently not widely used in South Africa to facilitate clinical decision-making or document treatment outcomes for patients with low back pain (LBP). This study investigated the internal consistency and clinical utility of a back-specific functional status measure, the Roland Morris Disability Questionnaire (RMDQ), and determined its ability to confirm the need for spinal fusion surgery.

Method: A retrospective, descriptive design was used with 42 patients with

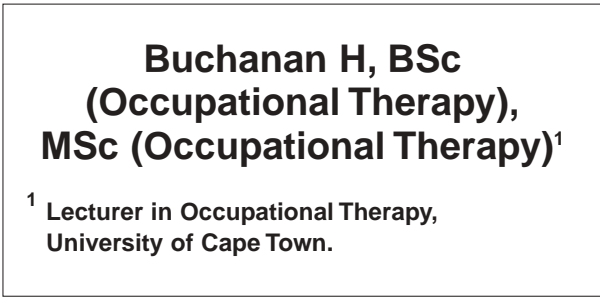
chronic mechanical low back pain who consulted a private Orthopaedic surgeon in Cape Town over a one year period. All patients completed the $R M D Q$ prior to their consultation. On completion of the medical examination, a rating for surgery was determined for each patient. The completed questionnaires were analysed using Statistical Package for the Social Sciences (SPSS).

Results: The mean $R M D Q$ score was 8.6 ( N=42; median=9.0; range=2-21). Cronbach's alpha showed a high internal consistency between items (.92). A categorical principal component analysis (CATPCA) identified two distinct dimensions in the $R M D Q$. Item reduction improved the internal consistency and thus the construct validity of the $R M D Q$. There was a low correlation between the surgeon's rating for surgery and $R M D Q$ scores $(r=.40 ; P<.01)$.

Conclusion: The $R M D Q$ shows some good psychometric properties but some adjustments could improve it. The $R M D Q$ cannot be used to predict the need for spinal fusion surgery.
\end{abstract}

\section{KEY WORDS: FUNCTIONAL STATUS MEASURES; LOW BACK PAIN; ROLAND-MORRIS DISABILITY QUESTIONNAIRE; PSYCHOMETRIC PROPERTIES.}

\section{INTRODUCTION}

One way of providing evidence of best practice is through the use of appropriate outcome measures (Corr and Siddons, 2005). A variety of functional status questionnaires measuring the impact of low back pain on performance of everyday activities are available to facilitate clinical decision-making and document treatment outcomes (Bombardier, 2000). These are, however, under-utilised due to uncertainty about which instruments to use and how they should be incorporated into practice (Bombardier, 2000, Beurskens et al., 1995).

To ensure that a measurement instrument is the most suitable choice for the intended purpose, it needs to be carefully evaluated. Instruments must have established validity, reliability, sensitivity and clinical utility (Corr and Siddons, 2005, McDowell and Newell, 1996). The Roland Morris Disability Questionnaire (RMDQ) is a back-specific outcome measure that has been used in a wide variety of clinical settings
(Roland and Fairbank, 2000). It has shown high internal consistency (Roland and Fairbank, 2000, Kopec and Esdaile, 1995) and good correlation with other measures of physical function (Roland and Fairbank, 2000). It has not, however, been tested in South Africa. To evaluate its appropriateness for a group of South African patients, and in the absence of a 'gold standard', construct and content validity are crucial in determining whether the RMDQ measures what it is supposed to measure (Beurskens et al., 1995).

The current study investigated the content and construct validity, internal consistency and clinical utility of the RMDQ in patients with chronic mechanical low back pain (CMLBP). It also set out to determine whether it could be used to confirm the need for spinal fusion surgery.

\section{METHOD}

This retrospective, descriptive study was conducted at a private orthopaedic surgery practice in Cape Town.

\section{Sample}

The study sample $(\mathrm{N}=42)$ included all patients with CMLBP who consulted a single surgeon over a one year period. Patients were included if they had experienced lumbar back pain for more than 3 months that affected their function. Patients were excluded if they had any concurrent medical conditions as these could interfere with their physical function.

\section{CORRESPONDENCE TO:}

Helen Buchanan

Department of Health \&

Rehabilitation Sciences

University of Cape Town

F45, Old Groote Schuur

Hospital Building, Observatory 7925

Tel: (021) 406-6383 (w)

Email: helen.buchnan@uct.ac.za 


\section{Instruments}

The RMDQ is a 24-item self-report questionnaire. Items in the scale were chosen for their relevance and focus on physical functions likely to be affected by back pain. The phrase 'because of my back pain' was added to make each item specific to back problems. Patients complete the questionnaire by ticking the items that apply to them 'today' (see Appendix 1). Scores are obtained by adding the number of positive responses and may vary between zero (no pain and normal function) and 24 (severe pain and dysfunction) (Roland and Fairbank, 2000, Roland and Morris, 1983).

The RMDQ was selected for the following reasons:

- It has been widely studied and is recommended as a particularly noteworthy back-specific functional status measure (Beurskens et al., 1995,
Deyo et al., 1998, Kopec and Esdaile, 1995, Roland and Fairbank, 2000, Roland and Morris, 1983, Stratford and Binkley, 1999).

- It is short, easy to understand and quick to complete (Beurskens et al., 1995, Roland and Fairbank, 2000, Roland and Morris, 1983)

- It can be used for patients with mild to severe disability (Roland and Morris, 1983) and is useful for monitoring patients in clinical practice (Roland and Fairbank, 2000).

\section{Procedure}

All patients completed a RMDQ using the method described by Roland and Morris (1983) before consulting the surgeon. The surgeon was blinded to patient RMDQ scores. The decision concerning the necessity for spinal fusion surgery (hereafter referred to as the 'rating for surgery') was based on specific medical investigations together with the surgeon's expertise and the patient's needs. The rating for surgery was documented as: 'yes' (definitely), 'almost' (more than 50\% chance), 'probably' (less than $50 \%$ chance) or 'no' (not needed). Demographic (age, gender, type of work) and anthropometric (height, weight) characteristics were also collected. Body mass index (BMI) was calculated from weight and height measurements. Patients were classified as having a satisfactory BMI, or as being overweight $(\mathrm{BMI}>25)$ or obese (BMI>30) (Department of Health and Human Services Centers for Disease Control and Prevention, 2006).

Confidentiality and anonymity were maintained by ensuring that patients could not be identified or linked to the data. Ethical approval was granted by

Table 1: Socio-demographic and medical data for subjects $(\mathrm{N}=42)$.

\begin{tabular}{|c|c|c|c|c|c|}
\hline \multirow[t]{2}{*}{ Variable } & \multirow[t]{2}{*}{ Categories } & \multicolumn{3}{|c|}{ No. of subjects } & \multirow[t]{2}{*}{$\%$ of total sample } \\
\hline & & Male & Female & Total & \\
\hline \multirow[t]{7}{*}{ Age } & $25-35$ & 0 & 6 & 6 & 14.3 \\
\hline & $36-40$ & 3 & 4 & 7 & 16.7 \\
\hline & $41-45$ & 5 & 4 & 9 & 21.4 \\
\hline & $46-54$ & 5 & 7 & 12 & 28.6 \\
\hline & $55-65$ & 1 & 5 & 6 & 14.3 \\
\hline & $66+$ & 1 & 1 & 2 & 4.8 \\
\hline & Total: & 15 & 27 & 42 & 100.1 * \\
\hline \multirow[t]{6}{*}{ Type of work } & Sitting and light physical & & 13 & & 34.2 \\
\hline & Sitting and medium physical & & 9 & & 23.7 \\
\hline & Medium to heavy physical & & 14 & & 36.8 \\
\hline & Missing data & & 2 & & 5.3 \\
\hline & Retired & & 4 & & 9.5 \\
\hline & Total: & & 38 & & 100.0 \\
\hline \multirow[t]{5}{*}{ Body mass index } & Acceptable & & 20 & & 47.6 \\
\hline & Overweight & & 13 & & 31.0 \\
\hline & Obese & & 6 & & 14.3 \\
\hline & Missing data & & 3 & & 7.1 \\
\hline & Total: & & 42 & & 100.0 \\
\hline \multirow[t]{5}{*}{ Rating for surgery } & Yes & & 7 & & 16.7 \\
\hline & More than $50 \%$ chance & & 7 & & 16.7 \\
\hline & Less than $50 \%$ chance & & 11 & & 26.2 \\
\hline & No & & 17 & & 40.5 \\
\hline & Total: & & 42 & & 100.1 * \\
\hline
\end{tabular}

\footnotetext{
* Percentages total more than $100 \%$ due to rounding off of decimal places
} 
the Faculty of Health Sciences Research Ethics Committee at the University of Cape Town.

\section{Data analysis}

Data were analysed using Statistical Package for the Social Sciences (SPSS). Total scores and the mean score for the RMDQ were calculated. Item totals were computed to identify items that were endorsed most frequently. Internal consistency was determined using Cronbach's coefficient alpha ${ }^{1}$. To reveal the inter-relationships between the items in the RMDQ, a categorical principal components analysis (CATPCA) ${ }^{2}$ was performed. Inspection of the component loadings for each item identified the items that were more discriminative in measuring functional status. Subsequent correlations and CATPCAs were performed on these items to determine whether item selection improved the reliability of the scale. Spearman's rho (r) was used to examine the relationship between the scores obtained on the RMDQ and the surgery rating of the patients.

\section{RESULTS}

Table 1 depicts socio-demographic and medical data for the study sample $(\mathrm{N}=42)$.

The mean RMDQ score was 8.6 $(\mathrm{N}=42 ; \quad$ median $=9.0 ; \quad$ range $=2-21)$. Thirty-six patients $(85.7 \%$; $\mathrm{N}=42)$ were included in the subsequent analyses. Six were excluded as their response patterns differed markedly from the rest. Items with less than 10 responses were excluded for further analysis, as there were insufficient responses to analyse their effects systematically (Table 2). Similarly, items endorsed by more than 33 patients (approximately $80 \%$ of the sample) were excluded. This ensured sufficient variation in responses. Altogether, 19 of the 24 RMDQ items were analysed.

Cronbach's alpha was computed with SPSS. Although alpha was high (.92)

Table 2: Items excluded from the analysis of the RMDQ.

\begin{tabular}{|l|l|}
\hline \multicolumn{1}{|c|}{ RMDQ item } \\
\hline 1. I stay at home most of the time because of my back. \\
\hline 15. My appetite is not very good because of my back pain. \\
\hline 19. Because of my back pain, I get dressed with help from someone else. \\
\hline 20. I sit down for most of the day because of my back. \\
\hline 24. I stay in bed most of the time because of my back. \\
\hline
\end{tabular}

demonstrating consistency amongst the 19 items, it did not identify which items were better at measuring functional status. A CATPCA was then done. This analysis identified two dimensions in the RMDQ, suggesting that responses referred to two different aspects of back pain. The eigenvalue ${ }^{3}$ was 7.6 , which explained $40 \%$ of the total variance. The first dimension explained $28 \%$ of the variance (eigenvalue $=5.3$ ) while the second explained $12 \%$ (eigenvalue $=2.3$ ). Closer inspection of the component loadings for each item identified those that contributed highly to either dimension 1 or dimension 2. Since items with low component loadings seemed unrelated to the remaining items (further analysis had not revealed further clustering of the items), a subsequent CATPCA was performed in which only the items that explicitly measured the phenomenon were included $(\mathrm{N}=9)$. Analysis of the selected nine items showed an improved eigenvalue (4.7), and explained $59 \%$ of the total variance. Figure 1 illustrates the interrelationship between the selected items which are considered to have made the most contribution to measuring functional status in the study sample. The relationship between items is illustrated by the angle between the vectors: the smaller the angle, the higher the relationship between them, and vice versa. An angle of $90^{\circ}$ implies that the items are unrelated. Items formed two clusters those between $\mathrm{A} 8$ and $\mathrm{A} 7$, and those between A9 and A6. Examination of these items showed that the former clus- ter seemed to be related to strategies to manage pain, while the latter appeared to relate to the impact of pain on function. The selection of items improved the consistency between the selected items and thus the construct validity of the adapted scale.

Figure 1: Component loadings for RMDQ items after removal of items not contributing to the measurement of functional status.

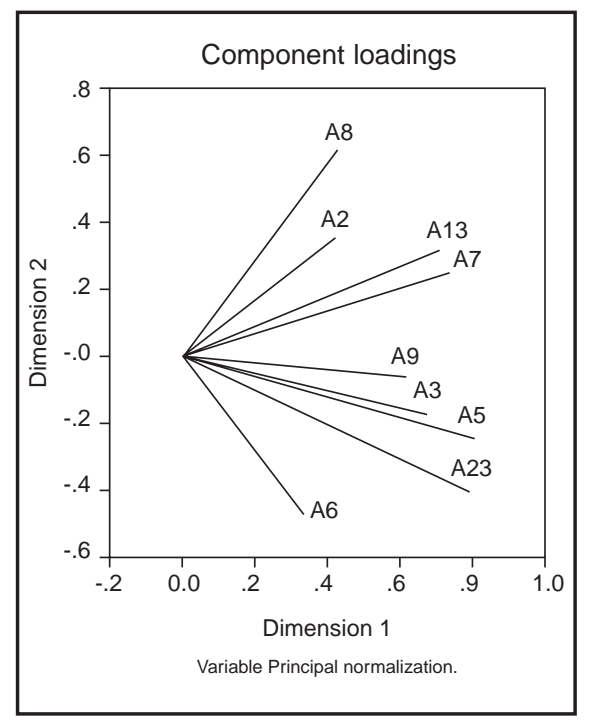

The relationship between the total RMDQ scores and the rating for surgery was low $(\mathrm{r}=.40 ; \mathrm{P}<.01)$. Although this is statistically significant, the correlation only explained $16 \%$ of the variance. It was therefore not opportune to execute further analyses to examine the predictive power of the RMDQ in discriminating between patients who were thought to need surgery and those who did not.

1 Cronbach's alpha is 'used to express the internal consistency reliability of a test' by examining the correlation between items in a test (McDowell and Newell, 1996, p. 499).

2 CATPCA performs a non-linear Principal Component analysis. The analysis forms the items into clusters of variables (or factors) that are related to each other but measure a distinct aspect of the phenomenon (McDowell \& Newell, 1996).

3 Eigenvalue: the proportion of variance explained by each factor 


\section{DISCUSSION}

The mean RMDQ score in this study was lower than that reported by Roland and Morris with patients seen in primary care (1983), and Lee et al (2001) with CMLBP patients at an out-patients clinic. This finding was not anticipated considering that the patients in the current study had CMLBP and were expected to have high RMDQ scores. The mean score did, however, fall within the range for chronic LBP defined by Stratford and Binkley (1999).

As the study was explorative in nature, the overall pattern of responses, rather than individual item responses, was of interest. In dichotomous scales such as the RMDQ, items where one alternative has a very high (or very low) endorsement rate are usually eliminated, as they do not improve the psychometric properties of the scale (Streiner and Norman, 1995). This prevents the occurrence of floor $^{4}$ and ceiling 5 effects which are problematic if the scale is used to evaluate change over time.

Some floor and ceiling effects have been described for the RMDQ (Atlas et al., 2003, Beurskens et al., 1995, Bombardier et al., 2001). As a result, several researchers have suggested that the RMDQ may be more sensitive than the Oswestry Disability Questionnaire (Fairbank et al., 1980) for detecting changes in patients with mild disabilities (Bombardier et al., 2001, Beurskens et al., 1995). Others, however, have advocated its use for patients with differing pain severity (Leclaire et al., 1997, Roland and Fairbank, 2000, Roland and Morris, 1983). Davidson and Keating (2002) suggested that the RMDQ lacked sufficient reliability and scale width for clinical application. Riddle and Stratford (2002) disagreed, however, referring to the extensive evidence supporting its use. Theoretically, increasing the number of response options for each item should improve the reliability of the scale (Stratford and Binkley, 1997, Beurskens et al., 1995), but studies comparing the RMDQ with multi-level response-option questionnaires have failed to demonstrate their superiority over the RMDQ (Kopec et al., 1995). This may be due to the item selection of the RMDQ being superior to competing measures (Stratford and Binkley, 1997). If this is true, then introducing a multilevel scoring scheme may enhance the properties of the RMDQ.

Previous studies identified RMDQ items that were less discriminative in measuring functional status. For example, Stratford and Binkley (1997) discovered six items that could be deleted from the scale, while Atlas et al (2003) deleted five items, replacing them with four new ones. Four of the items $(15,19,20$ and 24) identified by Stratford and Binkley (1997) and three (15, 19 and 20) by Atlas et al (2003) were also eliminated in the current study. Removing the less discriminative RMDQ items reduced the level of statistical 'noise' as evidenced by the improved construct validity of the scale. Removal of items can also, however, compromise the validity and reliability of an instrument (Kopec and Esdaile, 1995). Atlas et al (2003) found that reducing the number of RMDQ items increased the floor and ceiling effect rendering it less effective in distinguishing between patients with differing pain severities at a point in time and in assessing change over time.

Problems related to the design of the RMDQ, which could have affected the scoring and thus the study results included:

- Items are checked if they apply 'today', but there is no mechanism for identifying whether an item has been mistakenly or purposely omitted. The scoring system also does not permit a non-applicable response.

- Some patients wrote words (such as 'sometimes') rather than checking an item, suggesting that they may not have completed the scale based on their back pain 'today'.

- Statements such as 'I only walk short distances' may not have been completed accurately due to the absence of a quantitative description of what is meant by 'short'.

These deficiencies may result in inconsistent responses between patients and have been encountered previously (Lee et al., 2001, Stratford and Binkley, 1997, Turner et al., 2003). A further weakness of the RMDQ is its limited range (Lee et al., 2001, Roland and Fairbank, 2000). It should thus be used with other measures where necessary to obtain a comprehensive view of the impact of LBP on the person's life. The study supported Roland and Fairbank's (2000) assertion that the RMDQ is practical to administer and score which is a strength for its content validity.

The high internal consistency among the RMDQ items compares favourably with other studies (Kopec and Esdaile, 1995, Kopec et al., 1995, Jarvikoski et al., 1995, Stratford et al., 2000) and suggests that all items analysed were related and contributed to measuring functional status. According to Streiner and Norman (1995) Cronbach's alpha should not be higher than .90 . The high score could therefore, indicate a high level of item redundancy.

The identification of two dimensions in the RMDQ is a unique finding. No other studies were located in which a CATPCA has been conducted on the RMDQ although factor analysis has been used to develop other functional status measures for LBP (Delitto, 1994, Stratford and Binkley, 1997). The two dimensions identified, measure different aspects of the construct of 'function'. This finding could thus be used to address criticisms about the conceptual basis of the RMDQ (Delitto, 1994, Kopec and Esdaile, 1995, Kopec et al., 1995).

The low correlation between the RMDQ and the rating for surgery suggests that the RMDQ cannot be used to determine the need for spinal fusion surgery in patients with CMLBP. This indicates that the severity of functional impairment does not necessarily predict the need for surgery.

4 Floor effect: the patient scores at the low end of the scale making it difficult to detect deterioration in functional status.

5 Ceiling effect: if a patient scores at the top end of the scale it becomes difficult to measure an improvement in functional status (Streiner and Norman, 1995). 


\section{CONCLUSION AND RECOMMENDATIONS}

The study identified the RMDQ items that were most discriminative in measuring function in a sample of patients with CMLBP. The construct validity of the instrument was improved by removing the less discriminative items. The discovery of two distinct aspects of function in the instrument assists in defining the construct of function being measured.

The study findings indicate that while the RMDQ shows high internal consistency, some changes would improve it. When using the RMDQ as an outcome measure for individual patients, the following are recommended:

- Clear instructions must be given before completing the questionnaire to ensure it is completed based on the patient's back pain today.

- Tick boxes with 'yes' and 'no' options could be introduced to increase the reliability of the scoring (Appendix 2).

- For patients with CMLBP, items shown to be less discriminative could be removed and remaining items grouped according to the two dimensions identified by the CATPCA (Appendix 3).

- A broader range of response categories may increase the sensitivity of the RMDQ to detect change over time for patients scoring very high or very low on the scale at the start of treatment. This will enable clinicians to detect improvement or change resulting from treatment.

These recommendations (especially the latter two) would result in substantial changes to the instrument which could affect its current psychometric properties.

While the study has shown the RMDQ to have good internal consistency and clinical utility for patients with CMLBP, it supports the need for further research to study its merits together with other back-specific measures in different populations in South Africa. Practitioners are encouraged to consult the literature for guidance on using outcome measures such as the RMDQ, to inform clinical decision making and demonstrate the effectiveness of their treatment (Stratford and Binkley, 1999).

\section{ACKNOWLEDGEMENT}

Professor Herman Kruijsse for assisting with the statistical analysis.

\section{REFERENCES}

ATLAS, S., DEYO, R., VAN DEN ANCKER, M., SINGER, D., KELLER, R. \& PATRICK, D. (2003) The Maine-Seattle Back Questionnaire: a 12-item disability questionnaire for evaluating patients with lumbar sciatica or stenosis. Spine, 28, 1869-1876.

BEURSKENS, A., DE VET, H., KOKE, A., VAN DER HEIJDEN, G. \& KNIPSCHILD, P. (1995) Measuring the functional status of patients with low back pain. Assessment of the quality of four disease-specific questionnaires. Spine, 20, 1017-1028.

BOMBARDIER, C. (2000) Outcome assessments in the evaluation of treatment of spinal disorders. Spine, 25, 3097-3099.

BOMBARDIER, C., HAYDEN, J. \& BEATON, D. (2001) Minimal clinically important difference. Low back pain: Outcome Measures Journal of Rheumatology, 28, 431-438

CORR, S. \& SIDDONS, L. (2005) An introduction to the selection of outcome measures. British Journal of Occupational Therapy, 68, 202-206

DAVIDSON, M. \& KEATING, J. (2002) A comparison of five low back disability questionnaires: reliability and responsiveness. Physical Therapy, 82, 8-24.

DELITTO, A. (1994) Are measures of function and disability important in back care? Physical Therapy, 74, 452-460.

DEPARTMENT OF HEALTH AND HUMAN SERVICES CENTERS FOR DISEASE CONTROL AND PREVENTION (2006) BMI

- body mass index: about BMI for adults. http://www.cdc.gov/nccdphp/dnpa/bmi/adult_ BMI/about_adult_BMI.htm\#Interpreted, 2006, June 27.

DEYO, R., BATTIE, M., BEURSKENS, A., BOMBARDIER, C., CROFT, P., KOES, B., MALMIVAARA, A., ROLAND, M., VON KORFF, M. \& WADDELL, G. (1998) Outcome measures for low back pain research. Spine, 23, 2003-2009.

FAIRBANK, J., COUPER, J., DAVIES, J. \& O'BRIEN, J. (1980) The Oswestry Low Back Pain Disability Questionnaire. Physiotherapy, 66, 271-273.

JARVIKOSKI, A., MELLIN, G. \& ESTLANDER, A. (1995) Outcome of two multimodal back treatment programmes with and without intensive physical training. Journal of Spinal Disorders, 6, 93-98.
KOPEC, J. \& ESDAILE, J. (1995) Functional disability scales for back pain. Spine, 20, 1943-1949.

KOPEC, J., ESDAILE, J., ABRAHAMOWICZ, M., ABENHAIM, L., WOOD-DAUPHINEE, S., LAMPING, D. \& WILLIAMS, J. (1995) The Quebec Back Pain Disability Scale. Spine, 20, 341-352.

LECLAIRE, R., BLIER, F., FORTIN, L. \& PROULX, R. (1997) A cross-sectional study comparing the Oswestry and Roland-Morris Functional Disability scales in two populations of patients with low back pain of different levels of severity. Spine, 22, 68-71.

LEE, C., SIMMONDS, M., NOVY, D. \& JONES, S. (2001) Self-reports and clinicianmeasured physical function among patients with low back pain: a comparison Archives of Physical Medicine and Rehabilitation, 82, 227-231.

MCDOWELL, I. \& NEWELL, C. (1996) Measuring health: a guide to rating scales and questionnaires, New York, Oxford University Press.

RIDDLE，D. \& STRATFORD, P. (2002) Letters to the editor. Roland-Morris scale reliability. Physical Therapy, 82, 512-514. ROLAND, M. \& FAIRBANK, J. (2000) The Roland-Morris Disability Questionnaire and the Oswestry Disability Questionnaire. Spine, 25, 3115-3124.

ROLAND, M. \& MORRIS, R. (1983) A study of the natural history of back pain. Part I: Development of a reliable and sensitive measure of disability in low-back pain. Spine, 8 , 141-144.

STRATFORD, P. \& BINKLEY, J. (1997) Measurement properties of the RM-18. A modified version of the Roland-Morris Disability Scale. Spine, 22, 2416-2421.

STRATFORD, P. \& BINKLEY, J. (1999) Applying the results of self-report measures to individual patients: an example using the Roland-Morris Questionnaire. Journal of Orthopaedic \& Sports Physical Therapy, 29, 232-239.

STRATFORD, P., BINKLEY, J. \& RIDDLE, D. (2000) Development and initial validation of the Back Pain Functional Scale Spine, 25, 2095-2102.

STREINER, D. \& NORMAN, G. (1995) Health measurement scales. A Practical Guide to their Development and Use, New York, Oxford University Press.

TURNER, J., FULTON-KEHOE, D., FRANKLIN, G., WICKIZER, T. \& WU, R. (2003) Comparison of the Roland-Morris Disability Questionnaire and generic health status measures. A population-based study of workers' compensation back injury claimants Spine, 28, 1061-1067. 


\section{APPENDIX 1: THE 24-ITEM ROLAND-MORRIS DISABILITY QUESTIONNAIRE (RMDQ) (Roland \& Morris, 1983)}

When your back hurts, you may find it difficult to do some things you normally do. This list contains sentences that people have used to describe themselves when they have back pain. When you read them, you may find that some stand out because they describe you today. As you read the list, think of yourself today. When you read a sentence that describes you today, put a tick against it. If the sentence does not describe you, then leave the space blank and go on to the next one. Remember, only tick the sentence if you are sure it describes you today.

1. I stay at home most of the time because of my back.

2. I change position frequently to try and get my back comfortable.

3. I walk more slowly than usual because of my back.

4. Because of my back, I am not doing any of the jobs that I usually do around the house.

5. Because of my back, I use a handrail to get upstairs.

6. Because of my back, I lie down to rest more often.

7. Because of my back, I have to hold onto something to get out of an easy chair.

8. Because of my back, I try to get other people to do things for me.

9. I get dressed more slowly than usual because of my back.

10. I only stand for short periods of time because of my back.

11. Because of my back, I try not to bend or kneel down.

12. I find it difficult to get out of a chair because of my back.

13. My back is painful almost all the time.

14. I find it difficult to turn over in bed because of my back.

15. My appetite is not very good because of my back pain.

16. I have trouble putting on my socks (or stockings) because of the pain in my back.

17. I only walk short distances because of my back.

18. I sleep less well on my back.

19. Because of my back pain, I get dressed with help from someone else.

20. I sit down for most of the day because of my back.

21. I avoid heavy jobs around the house because of my back.

22. Because of my back pain, I am more irritable and bad tempered with people than usual.

23. Because of my back, I go upstairs more slowly than usual.

24. I stay in bed most of the time because of my back.

Score

The score is the total number of items checked, i.e., from a minimum of 0 to a maximum of 24 .

\section{APPENDIX 2: ADAPTED ROLAND-MORRIS DISABILITY QUESTIONNAIRE}

When your back hurts, you may find it difficult to do some things you normally do. This list contains sentences that people have used to describe themselves when they have back pain. When you read them, you may find that some stand out because they describe you today. As you read the list, think of yourself today. When you read a sentence that describes you today, place a tick in the 'yes' column. If the sentence does not describe you today, then tick the 'no' column. Remember, only tick the 'yes' column if you are sure it describes you today.

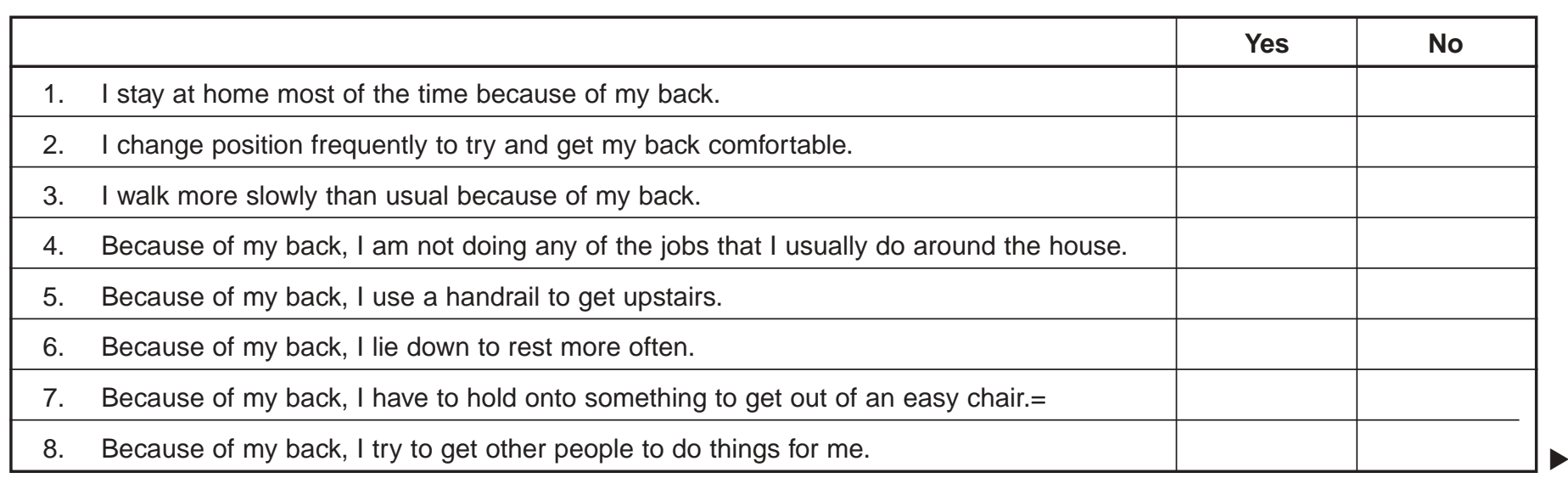




\begin{tabular}{|c|c|c|}
\hline & Yes & No \\
\hline 9. I get dressed more slowly than usual because of my back. & & \\
\hline 10. I only stand for short periods of time because of my back. & & \\
\hline 11. Because of my back, I try not to bend or kneel down. & & \\
\hline 12. I find it difficult to get out of a chair because of my back. & & \\
\hline 13. My back is painful almost all the time. & & \\
\hline 14. I find it difficult to turn over in bed because of my back. & & \\
\hline 15. My appetite is not very good because of my back pain. & & \\
\hline 16. I have trouble putting on my socks (or stockings) because of the pain in my back. & & \\
\hline 17. I only walk short distances because of my back. & & \\
\hline 18. I sleep less well on my back. & & \\
\hline 19. Because of my back pain, I get dressed with help from someone else. & & \\
\hline 20. I sit down for most of the day because of my back. & & \\
\hline 21. I avoid heavy jobs around the house because of my back. & & \\
\hline 22. Because of my back pain, I am more irritable and bad tempered with people than usual. & & \\
\hline 23. Because of my back, I go upstairs more slowly than usual. & & \\
\hline 24. I stay in bed most of the time because of my back. & & \\
\hline TOTALS & & \\
\hline
\end{tabular}

SCORE (total number of ticks in the 'yes' column)

The score may range from a minimum of 0 to a maximum of 24 .

\section{APPENDIX 3: RMDQ ITEMS THAT MADE THE MOST CONTRIBUTION TO THE MEASUREMENT OF FUNCTIONAL STATUS}

When your back hurts, you may find it difficult to do some things you normally do. This list contains sentences that people have used to describe themselves when they have back pain. When you read them you may find that some stand out because they describe you today. As you read the list think of yourself today. When you read a sentence that describes you today, tick the 'yes' column. If the sentence does not describe you, then tick the 'no' column. Remember, only tick the 'yes' column if you are sure the item describes you today.

\begin{tabular}{|c|c|c|c|}
\hline \multirow[t]{2}{*}{ Original item no. } & \multirow{2}{*}{$\begin{array}{l}\text { Dimension \& Item } \\
\text { Dimension 1: Strategies to manage pain }\end{array}$} & \multicolumn{2}{|c|}{$\begin{array}{l}\text { Response (tick column } \\
\text { that applies today) }\end{array}$} \\
\hline & & Yes & No \\
\hline 2 & I change position frequently to try and get my back comfortable. & & \\
\hline 7 & Because of my back, I have to hold onto something to get out of an easy chair. & & \\
\hline 8 & Because of my back, I try to get other people to do things for me. & & \\
\hline \multirow[t]{2}{*}{13} & My back is painful almost all the time. & & \\
\hline & Dimension 2: Impact of pain on function & & \\
\hline 3 & I walk more slowly than usual because of my back. & & \\
\hline 5 & Because of my back, I use a handrail to get upstairs. & & \\
\hline 6 & Because of my back, I lie down to rest more often. & & \\
\hline 9 & I get dressed more slowly than usual because of my back. & & \\
\hline \multirow[t]{2}{*}{23} & Because of my back, I go upstairs more slowly than usual. & & \\
\hline & Score & & \\
\hline
\end{tabular}




\title{
Compressed Air Massage: Repeated Treatment Causes Less Muscle Oedema Than a Single Treatment
}

\begin{abstract}
Compressed air massage is a new treatment modality that has been shown to cause skeletal muscle capillary dilation for up to 24 hours after a single treatment and significantly hastens healing of diabetic ulcers. This study compares the effect of one treatment of a single muscle group, with repeated treatments of several muscle groups.
\end{abstract}

Methods: Four vervet monkeys underwent one, $15 \mathrm{~min}$, treatment of compressed air massage at 1 Bar, to the tibialis anterior muscle and four animals received similar treatment to the whole lower leg on three consecutive days. The tibialis anterior of the treated and untreated limbs was biopsied immediately after the final treatment. Muscle fibre diameters were measured from l $\mu m$ thick toluidine blue stained resin embedded sections using light microscopy and computerized image analysis software.

Results: For treatment of the whole lower limb, the mean fibre diameter increased by $6.0 \%$ from $47.31 \pm 13.4 \mu \mathrm{m}$ (95\%CI:46.47-48.16) in control biopsies to 50.14 $\pm 13.93 \mu \mathrm{m}$ (95\%CI:49.26-51.02) in treated muscle $(p<0.001)$. Treatment of a single muscle showed an increase in diameter of 11.3\%, from 48.21 $\pm 12.68 \mu \mathrm{m}$ (95\% CI:47.31-49.11) to $53.63+14.29 \mu \mathrm{m}(95 \%$ CI:52.61-54.66 ( $p<0.001)$. Treatment of a single muscle caused significantly more oedema than treatment of the whole limb $(p<0.001)$.

Conclusions: Repeated treatment causes skeletal muscle oedema, and this appears to be dose related. Skeletal muscle oedema after three treatments is less than after a single treatment. Further studies on the use of compressed air massage on injured muscle are warranted.

KEY WORDS: COMPRESSED AIR MASSAGE, SKELETAL MYOFIBRES, LIGHT MICROSCOPY, MORPHOMETRY.

\section{INTRODUCTION}

Compressed air massage is a new treatment modality that may be useful in treating skeletal muscle injuries (Mars 2003). Using unheated air, compressed air massage reduces skin temperature, increases skin blood flow during treatment (Mars et al 2005) and causes skeletal muscle capillary dilation for up to 24 hours after a single treatment (Gregory and Mars 2005). When applied to the lower limbs of patients with diabetes, as

\section{CORRESPONDENCE TO:}

Prof Maurice Mars

Dept of TeleHealth

Nelson R Mandela School of Medicine

University of KwaZulu-Natal

Private Bag 7

Congella

4013

Tel: (031) 260-4543

Fax: (031) 260-4737

Email: mars@ukzn.ac.za an additional part of the daily treatment regimen, compressed air massage significantly hastens the healing of diabetic ulcers (Mars and Desai 2005).

Compressed air massage can be varied by using different applicator heads or changing the air pressure. The heads differ in the size, number and configuration of the outlet holes through which the air leaves the applicator head. These range from a single $5 \mathrm{~mm}$ diameter hole to multiple pinholes in a linear array or a single narrow slit. The applicator head with the single $5 \mathrm{~mm}$ hole has been shown to transmit the greatest pressure to subcutaneous tissue and is therefore more likely to cause tissue damage (Mars 2003).

A single, 10 minute treatment, at 1 Bar pressure, using the applicator head with the single $5 \mathrm{~mm}$ diameter hole has been shown to cause ultrastructural changes to skeletal myofibres. These include juxta-nuclear and intermyofibrillar oedema, electron-lucent spaces filled with swollen mitochondria and elements of the sarcoplasmic reticulum (SR) and occasional aggregates of glycogen and other non-contractile organelles in oedematous, sub-sarcolemmal regions, immediately after treatment. Myofibre oedema was significant, with a $17.2 \%$ increase in mean fibre diameter after treatment. $24 \mathrm{hr}$ after treatment, intermyofibrillar oedema was reduced, but SR swelling remained and many fibres were characterised by focal and large areas of myofibrillar disorganisation. Myofibre oedema, while present, was reduced to $5.5 \%$. With the exception of occasional swollen elements of the SR and a single internalised nucleus, myofibres morphology had returned to normal 6 days after treatment (Gregory and Mars 2004). These changes were less frequent and of less severity than those noted after a 10 minute treatment using deep transverse friction (Gregory et al 2003, Gregory and Mars 2004). 